\title{
THE SEVEN TYPES OF YELLOW SAPPHIRE AND THEIR STABILITY TO LIGHT
}

\author{
By Kurt Nassau and G. Kay Valente
}

Colorless to yellow to intense orange sapphire will react quite differently to light or heat depending on the nature of the material and the origin of the color. The authors determined that there are actually seven types of "yellow" sapphire on the market today, which differ in the cause of color and the stability of the color to light: type 1-natural, light-stable color center; type 2-natural or irradiation-produced, fading color center; type 3 -iron containing, not heated, light stable; type 4-iron containing, heated, light stable; type 5-surface-diffused additive, light stable; type 6-synthetic, light stable; and type 7-synthetic irradiated, fading. The authors examined more than 150 samples of yellow sapphire to confirm the seven types and document their different reactions to light, heat, and/or irradiation. One unexpected finding was that type 1 material can fade on heating even below $200^{\circ} \mathrm{C}$, but that the color is restored by exposure to light.

\section{ABOUT THE AUTHORS}

Dr. Nassau is a research scientist residing in Bernardsville, New Jersey; Ms. Valente is vice-president of American Gem Market System, Moraga, California.

Acknowledgments: The authors gratefully acknowledge the loan of study malerial from R. C. Miller and G. V. Rogers, both of New York City; from $R$. Vinyard, of Lake Oswego, OR; and from the Gemological Institute of America, Santa Monica, CA. The GIA Research Department was also extremely helpful.

(c) 1988 Gemological Institute of America
$\mathrm{Y}$ ellow sapphires have surged in popularity in recent years (figure 1), which has prompted further study into their properties and, especially, the effects of treatment by heat or irradiation. An important problem is the distinction between yellow sapphires that are color stable and those that fade under normal conditions. At present, the only practical way for the gemologist to separate these two materials is by an extended exposure to light or by some sort of heating test. Webster and Anderson (1983) suggest that three hours in bright sunlight or a few minutes of heating at $230^{\circ} \mathrm{C}$ will fade (and thus identify) irradiated Sri Lanka material. Dealers in the Far East routinely test yellow sapphires by heating them in the flame of a candle for a few seconds or placing them on a sunlit windowsill for a few days. A heating test that is too short, however, can be unreliable, since the stone-particularly a large one-may not reach the required temperature; partial fading can also occur with material that is stable to light, as discussed below.

In the course of testing the reaction of the color of a wide variety of gem materials with respect to light and heat, one of us $(\mathrm{KN})$ came to note a simple relationship: among all the materials tested, those that fade rapidly on exposure to light also lose their color when heated at $200^{\circ} \mathrm{C}$ for about one hour (e.g., Maxixe-type beryl and some brown topaz), and materials that do not lose their color after one hour at $200^{\circ} \mathrm{C}$ also do not fade significantly in light (e.g., amethyst and smoky quartz, blue and some brown topaz, and red tourmaline). One obvious anticipated exception is chameleon diamond, in which one color component appears to fade (Nassau, 1984). As a result of the present work, another one is yellow sapphire. With these two exceptions, heating at $200^{\circ} \mathrm{C}$ for about one hour can be a useful test for color stability (Nassau, to be published).

When we became aware of the variable reaction of 




Figure 1. Yellow sapphires have become increasingly popular over the last few years. In this suite of fine yellow sapphires set with diamonds and emeralds, the largest pear-shaped yellow sapphire is 22 $\mathrm{ct}$ and the largest heart shape is $17 \mathrm{ct}$. Courtesy of Harry Winston, Inc.

yellow sapphires to this test, we sought to establish the possible range of reaction of different types of yellow sapphire to light, heat, and irradiation. In the course of this research, we determined the need for distinguishing the various types of yellow sapphire, so a provisional classification system was developed on the basis of our experience and the previous literature. The proposed classification and the research study are described below. A number of yellow sapphires, natural and synthetic, treated and untreated, were tested for their reaction to heat, light, and irradiation. The research confirmed the proposed classification system; recognition of the seven types will permit the gemologist to deduce for any yellow sapphire* both the

${ }^{*}$ Note that the general use of the term yellow here is intended to cover the wide range from the palest of yellows through yellow-orange to dark orange verging on brown. This range corresponds to an intensification of the same hue, with a dominant wavelength near $580 \mathrm{~nm}$. color origin and the stability of the color to light and to heat exposure by conventional gemological testing.

\section{A CLASSIFICATION FOR YELLOW SAPPHIRE}

Early gemologists believed that there was only one type of yellow sapphire, also called "oriental topaz" or "topaz-sapphire" (Bauer, 1904). Smith (e.g., in his 10th edition, 1949) said that yellow sapphire lost its color when heated and that radium (i.e., irradiation) either deepened the color or developed it in a colorless stone. More recent studies have expanded our knowledge of this behavior |Crowningshield and Nassau, 1981; Fryer et al., 1983a, 1983b; Koivula, 1986; Nassau, 1980, 1981, 1984; Schiffmann, 1981; Schmetzer and Bank, 1980; Schmetzer et al., 1983). Some studies (e.g., Schmetzer et al., 1983) have suggested that the yellow color may arise from color centers, or iron, or both. We also know that some yellow sapphires 


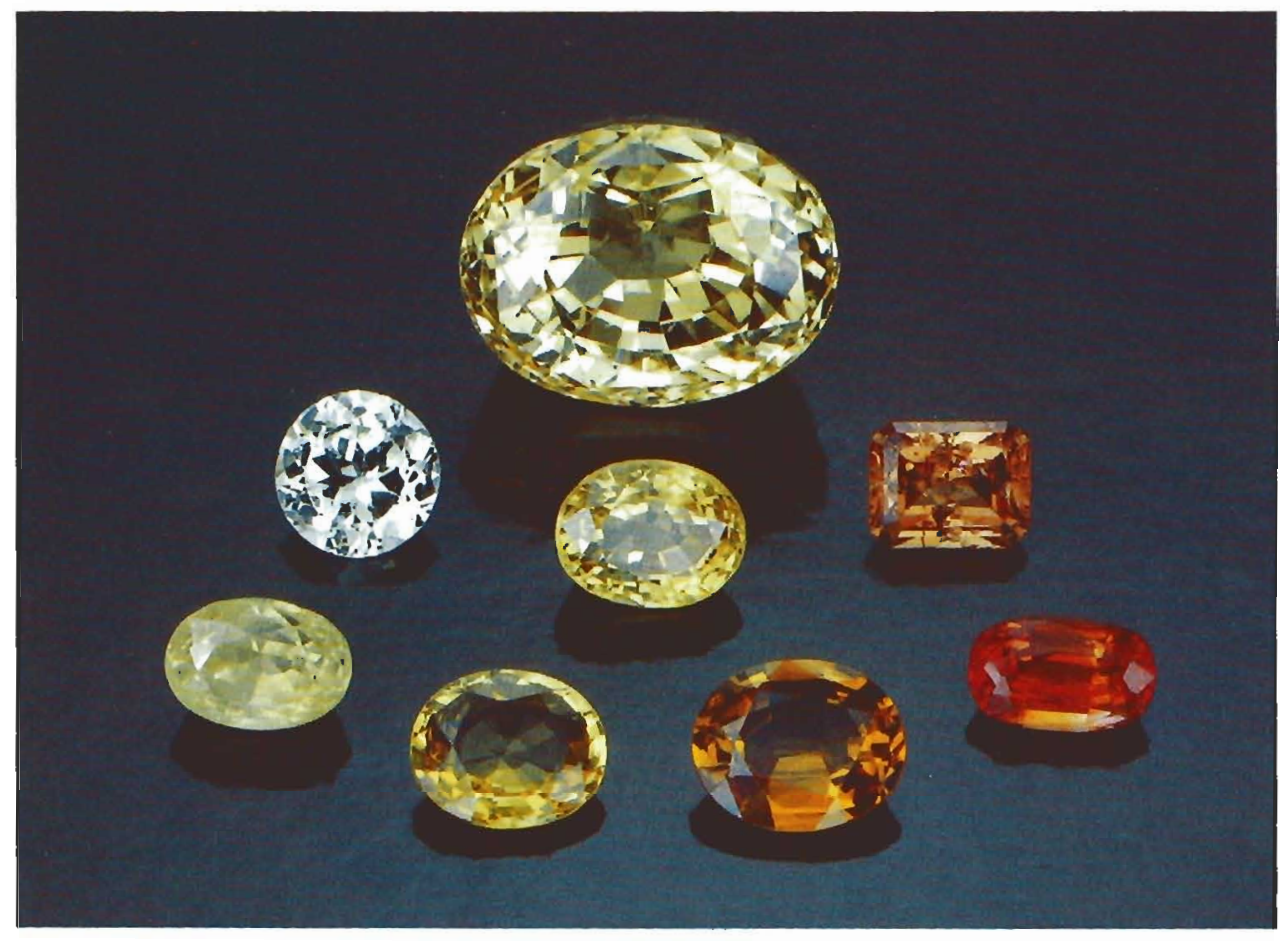

Figure 2. Exanples of the range of colors of types 1 and 2 yellow sapphires studied; the largest stone weighs $11.80 \mathrm{ct}$. Photo (c) Tino Hammid.

colored by color centers fade in light, while others do not (Nassau, 1981, 1984). Synthetic yellow sapphires, too, may be colored by an impurity (usually nickel) or by a color center (Schmetzer et al., 1983|. Lastly, color may be induced by diffusing iron (or nickel) into the surface of a sapphire (Nassau, 1980). On the basis of the information

Figure 3. Examples of the range of colors of types 1,2, and 3 pale tan and brown sapphires studied; the largest piece is $6 \mathrm{~mm}$ long.



published to date and on experience, we propose a classification that defines seven types of yellow sapphire:

Type 1: Pale yellow to orange, with color originating from a natural stable color center. Usually from Sri Lanka. Color is stable to light.

Type 2: Pale yellow to deep orange, resulting from the irradiation of colorless sapphire, with color originating from a light-fading color center. May have been colored when found, but faded when exposed to light; color can be restored by irradiation, but will fade once again.

Type 3: Pale yellow to orange, iron containing, but has not been heated to high temperature, as in type 4. Color caused by iron (usually up to 0.8 wt. \%), with other elements possibly present in smaller amounts. Typically from Thailand, Australia, or Tanzania. Color is stable to light.

Type 4: Yellow to deep orange-brown, color created by heating paler iron-containing material. Color probably caused by iron; it is stable to light.

Type 5: Yellow to deep orange-brown, containing iron (or nickel) in surface layer only; impurity has been diffused in at high temperature. Color is stable to light, but the thin colored zone may be lost on recutting.

Type 6: Synthetic sapphire with nickel and/or other elements added; may also have been subjected to heat treatment. Color is stable to light. 
Type 7: Synthetic sapphire with color induced by irradiation. Fades to colorless in light.

ln types 1 and 2, iron may be present /usually less than $0.1 \%$ ) without affecting color. However, some stones could conceivably contain more than one type of color-causing agent. Types 2 and 7, especially, can co-exist with other types; thus, a pale yellow type 1 sapphire may be irradiated to a dark orange color, which is then type $1+2$, but in light this will fade back to the original type 1 pale yellow. All of these types of yellow can also coexist with a chromium-produced pink, resulting in an analogous group of seven types of "padparadscha" sapphire (Crowningshield, 1983).

\section{MATERIALS AND METHODS}

More than 150 colorless and pale colored sapphires, both rough and faceted, were used in this study. They came from Chanthaburi-Trat (Thailand), Sri Lanka, Umba Valley (Tanzania), Montana, and some unidentified locations. A wide range of synthetic sapphires, including Verneuil, Czochralski, and flux products, were also tested. Some of the natural gems had been heat treated while others had not, as determined by microscopic examination.

The range of colors of those gem-quality yellow sapphires studied that were identified as types 1 and 2 are illustrated in figure 2 . That of the milky and clear pale tan and brown material, including types $1-3$, is shown in figure 3 ; and typical type 4 material is shown in figure 4.
Heating was performed in resistance-heated muffle furnaces, with the samples buried in clean, acid-washed sand for the higher temperatures. Irradiations were performed in a cobalt- 60 gamma cell at a rate of one Mrad per hour (Nassau, 1983). In all instances, the color reached saturation, as visually determined, in much less than eight hours (the minimum time used). A few spot checks showed that X-rays produced the same color reaction as gamma rays, as had been expected (Fryer et al., 1983a; Pough and Rogers, 1947). For exposure to unfiltered short-wave ultraviolet radiation (USW), samples were placed $5 \mathrm{~cm}$ from the bare bulb (4 watts) of a Mineralight fluorescent lamp.

Many of the faceted stones were matched on the GIA ColorMaster, both before and after a variety of treatments. These ColorMaster measurements were also converted to the AGMS (American Gem Market System, Moraga, CA) overall grade point scale, where 0 is colorless and 100 is the most saturated land, therefore, most desirable) sapphire to be designated yellow (Valente, 1986). The 100 grade-point material is sold in the trade for about five times what the 60 gradepoint material goes for, while the latter sells for about $50 \%$ more than the 40 grade-point material. The National Bureau of Standard ISCC/NBS collection of color chips (Kelly and Judd, 1955) was also used for visual comparison as well as inferred by computer conversion from the ColorMaster values.

The colors of the sapphires studied extend on

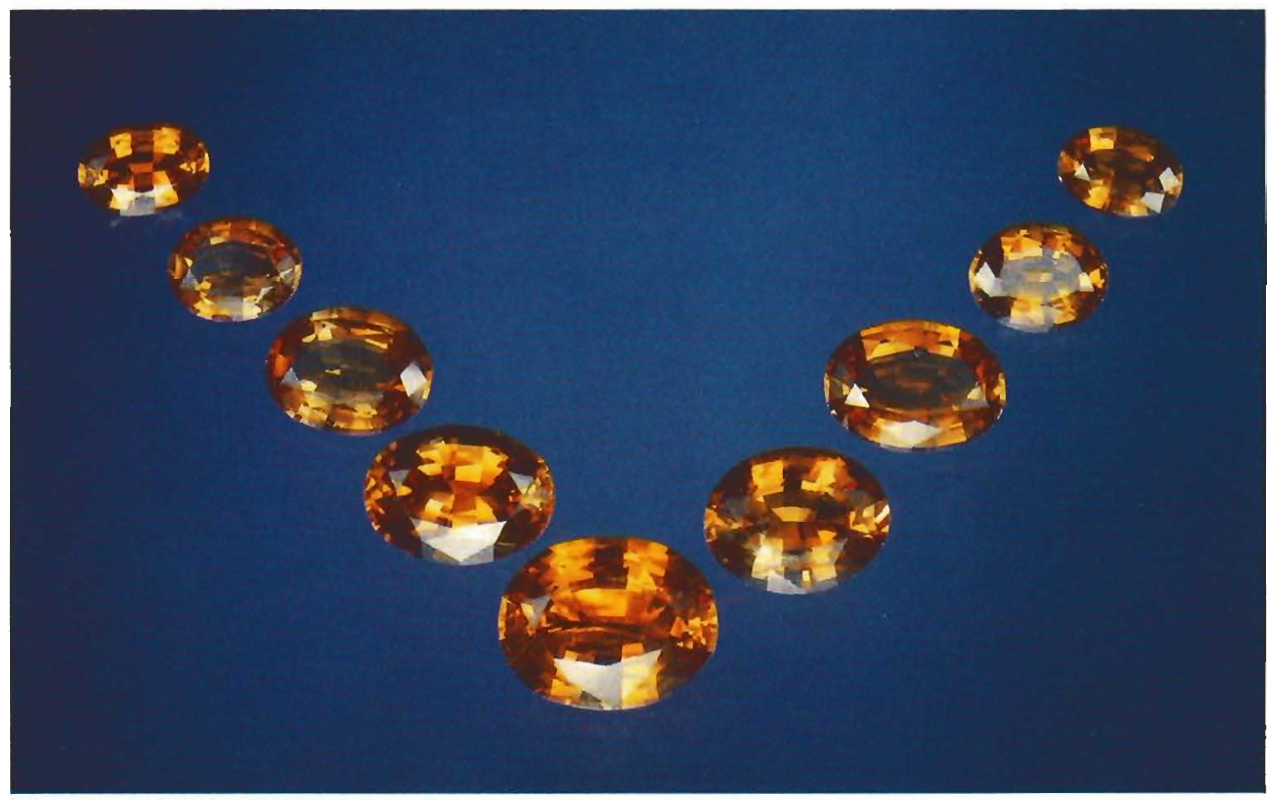

Figure 4. Typical heated type 4 yellow sapphires. Photo (C) Harold es) Erica Van Pelt. 
the ISCC/NBS scale from no. 263 white, through 89 pale yellow, 87 moderate yellow, 83 brilliant yellow, 82 vivid yellow, 66 vivid orange yellow, 48 vivid orange, to 51 deep orange; there are additional intermediate points. Typical ColorMaster readings (all A) are for no. $48-50 / 50 / 00$ and 96/99/00; for no. 82-44/61/0 and 38/46/0; and for no. $87-22 / 42 / 06$. The dominant wavelength is in the 575- to 587-nm range, so that an essentially single-dimensional color (hue), varying only in saturation, is being measured.

\section{TESTING AND RESULTS}

Forty gem-quality type 1 stones (group 1) were ColorMaster matched by one of us $(\mathrm{GKV})$ four to eight times each, before and after a variety of tests. These tests included heating for one hour at $100^{\circ} \mathrm{C}$ or $200^{\circ} \mathrm{C}$ (abbreviated $\mathrm{H} 100$ and $\mathrm{H} 200$, respectively); exposing for one day to gamma rays, for 12 hours to unfiltered short-wave ultraviolet radiation (USW), or for one or two days in sunlight; and/ or storing for three days in a dark safe. The results of the various tests for three typical stones from group 1 are shown in figure 5 against the AGMS grade point scale; approximate color descriptions are also included in this figure. Data for the $\mathrm{H} 200$ heating step, a subsequent USW exposure, and a subsequent $\mathrm{H} 100$ heating (but only if performed in this sequence) are summarized in figure 6 for all of the stones in group 1.
A second group, including 10 of the group 1 gemstones, 44 additional cut stones (including colorless type 2 and heat-treated type 4 stones), and 53 pieces of rough (including those of figure 3), were irradiated and heated, some to successively higher temperatures (at $50^{\circ} \mathrm{C}$ intervals), to study the formation and disappearance of types 1 and 2 color centers. Samples were also exposed to sunlight as well as to incandescent and fluorescent artificial light, some before and some after irradiation and/or heating.

All the sapphires tested, including the heattreated type 4 stones, turned a significantly darker yellow on gamma-ray or X-ray irradiation, as much as over 90 grade points. Figure 7 shows the range of colors produced by varying amounts of gamma irradiation in type 2 colorless sapphire. The USW treatment produced a smaller darkening, as shown at $b$ in figure 6 , with an average of approximately 25 grade points; two 24-hour USW treatments were sometimes necessary to return a heated $\mathrm{H} 200$ stone to a color darker than the original.

Successive heating steps of type 1 and irradiated types 2 and $1+2$ material showed that some color was lost on heating for one hour at as low a temperature as $60^{\circ} \mathrm{C}$. More color loss occurred at $100^{\circ} \mathrm{C}, 150^{\circ} \mathrm{C}, 200^{\circ} \mathrm{C}, 300^{\circ} \mathrm{C}$, and $400^{\circ} \mathrm{C}$; all traces of color were lost by $500^{\circ} \mathrm{C}$ or $600^{\circ} \mathrm{C}$. It should be noted that fractures typical of those caused by heating were seen around inclusions after expo-

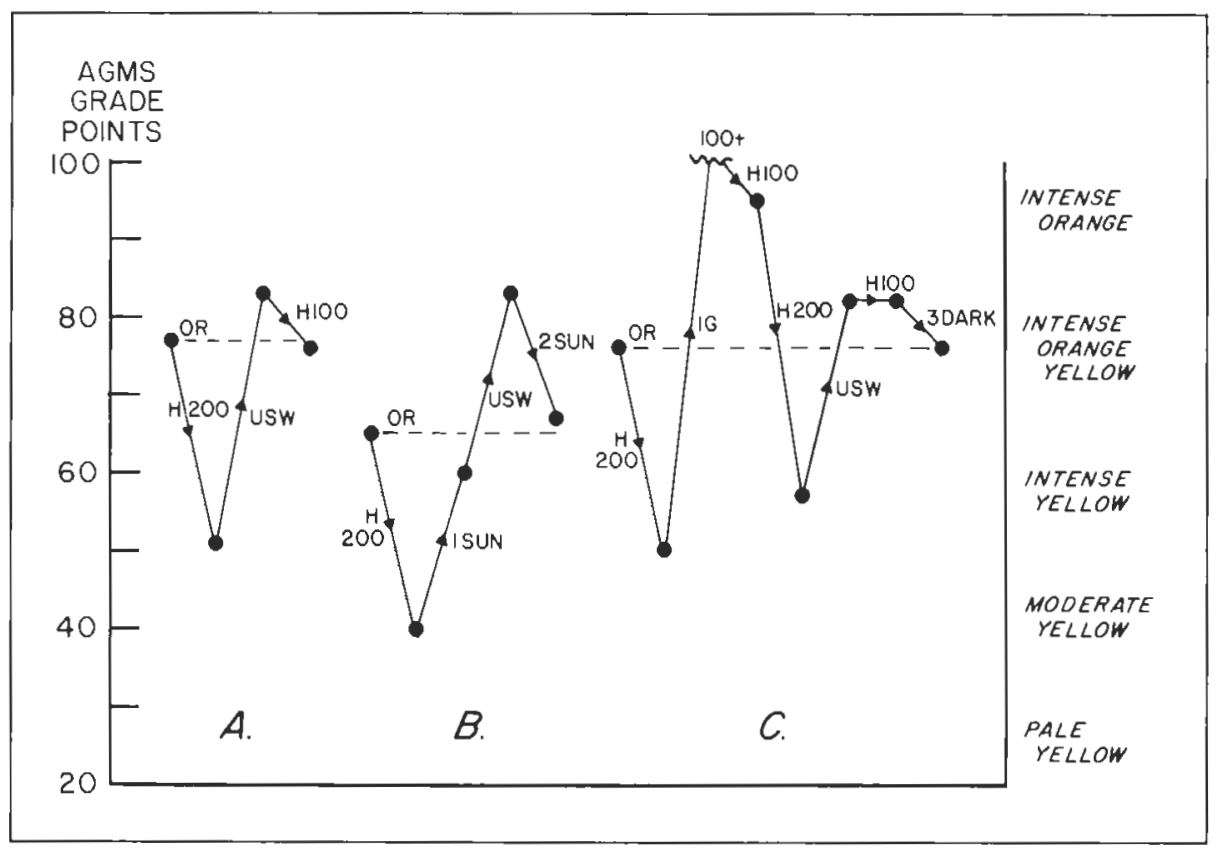

Figure 5. This graph charts, on the AGMS grade point scale, the changes in color produced by various types of treatment in three typical type 1 yellow sapphires. $O R$ is the original color, $H 200$ is heating at $200^{\circ} \mathrm{C}$ for one hour, H100 is heating at $100^{\circ} \mathrm{C}$ for one hour, ISUN and 2SUN are exposure to one or two days of sunlight, $1 \mathrm{G}$ is exposure for one day to gamma radiation, $3 D A R K$ is storing for three days in a dark safe, and USW is exposure for 12 hours to unfiltered shortwave ultraviolet radiation. 


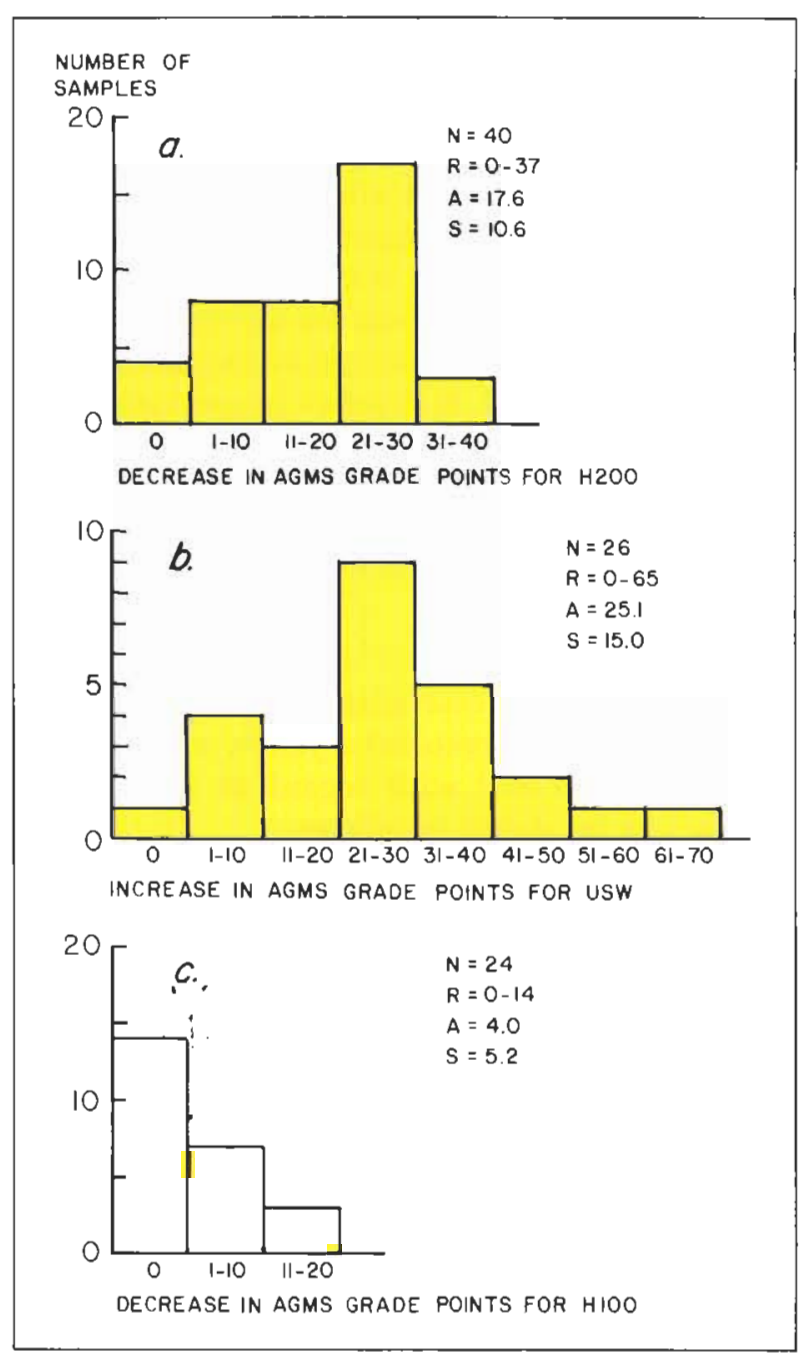

Figure 6. These statistical bar charts for type 1 yellow sapphires show (a) the loss of color (as expressed in decreased AGMS grade points) after an $H 200$ heating, (b) the improvement in color (increased AGMS grade points) after a subsequent USW treatment, and (c) the subsequent loss of color after a final H100 heating. $N$ is the number of samples, $R$ the range of point values, $A$ their average, and $S$ their standard deviation.

sure to temperatures as low as $400^{\circ} \mathrm{C}$. As seen at $a$ in figure 6, 36 out of 40 light-stable yellow sapphires lost significant color with an $\mathrm{H} 200$ heating (17.6 grade points, averaged for all 40 ), while the $\mathrm{H} 100$ heating at $c$ in this figure, which was conducted after the USW exposure, produced much smaller changes (average 4.0 grade points). Both of these bar graphs indicate that the color change produced by the different treatments varies greatly from stone to stone. In some instances, the use of $\mathrm{H} 100$ after USW resulted in a return of the original color ( \pm 2 grade points), as at $A$ in figure 5 . At other times, H100 produced no change, as in one of the two such treatments at $C$ in this figure, where a mere resting in the dark restored the original color. In all other specimens, however, the irradiation-induced color did not appear to change if the stones were stored in the dark.

Exposure to bright light, typically two days in bright California sun, or longer periods under less bright conditions (both outdoors and behind a window), was found to be the simplest and preferred way to return the original color, as at $B$ in figure 5. Although this had been expected to apply to irradiated types 2 and $1+2$ yellow sapphires, it also worked for these types of stones when faded by heating, regardless of the temperature to which they were heated and the extent of fading.

This unexpected behavior was at first attributed to the ultraviolet rays present in sunlight. However, a yellow glass filter with an optical density of 2.0 at $410 \mathrm{~nm}$ was used to remove the ultraviolet component from incandescent light; this slowed down light-restoration of the heatremoved color but did not prevent it. Accordingly, even visible light restores the stable-state color from either direction, both from the irradiationproduced darker colors as well as from the heatproduced lighter colors.

Figure 7. Examples of type 2 colorless sapphires irradiated to various colors; the largest stone weighs $21.34 \mathrm{ct}$.








Figure 8. The behavior on exposure to light, heat, and irradiation of a specific type 1 lightstable medium orange-yellow sapphire (left) is compared to that of any type 2 colorless sapphire (right).

All of these results are summarized in figure 8 for a specific type 1 yellow sapphire (left) and for a type 2 yellow sapphire (right). The temperatures shown at the left apply only to this specific specimen, for which the stable color is a medium orange-yellow. The material is returned to this color by light from either direction, after darkening by irradiation or after fading by heat treatment. The stable-state color of another type 1 sample could be anywhere on this scale, with shifted temperatures. It can be seen that the type 2 sapphire on the right is merely a special case of the type 1 on the left, with the stable state here being colorless.

Additional irradiation experiments followed by light and/or heat exposure were performed on a variety of types 3 and 6 materials, with results analogous to those for the irradiation-induced type 2 yellow component. Heating to as high as $1700^{\circ} \mathrm{C}$ did not change the ability to produce type 2 color by irradiation, which also was observed in the presence of any other types of yellow color. The fading with heat or light of both types 1 and 2 colors also did not appear to be affected by a hightemperature treatment. The type 7 irradiated syn- thetic sapphire behaved the same as the type 2 natural. Type 1 behavior was not observed in any synthetic sapphire, presumably because of the absence of the required precursor. The color of type 3 yellow sapphire is not affected by light or by heating except at the highest temperatures lapproaching $2000^{\circ} \mathrm{C}$, when it is converted to type 4 material. Irradiation can produce a deeper type $3+$ type 2 yellow, but the extra type 2 component fades in light as expected. R. Hughes (unpublished observation, 1986 ) has reported that gentle heating of type 4 Sri Lanka material produces a darkening of the yellow, with a return to the original color on cooling back to room temperature.

\section{CONCLUSIONS}

This series of tests essentially confirms the proposed classification system for yellow sapphires. In simplified form and with regard to stability to light, it can be stated as follows:

Type 1: Natural stable color center

Type 2: Natural or laboratory-irradiated fading color center

Type 3: Natural iron-produced stable color

Type 4: Heat-developed stable color

Type 5: Surface-diffused additive color

Type 6: Synthetic with impurity-caused color

Type 7: Synthetic with irradiated fading color center

There have been many reports in the gemological literature on the nature and properties of one or more of these types of yellow sapphire. Some of the more relevant and/or comprehensive studies are listed here in reverse chronological order, with an indication of the specific types of yellow sapphire covered; many additional relevant references will be found cited in these studies: Koivula (1986: 1 to 4); Nassau (1984: 1 to 4); Schmetzer et al. (1983: 1 to 6); Fryer et al. (1983a: I and 2); Fryer et al. (1983b: 3); Nassau (1981: 4 and 5); Crowningshield and Nassau (1981: 4 and 5); Schiffmann (1981:2); Schmetzer and Bank (1980: 3 and 4); Nassau (I980: 6 and 7); and Pough and Rogers (1947: 2). Recent specific locality studies include those on the Umba Valley, Tanzania (Hänni, 1986) and on Chanthaburi-Trat, Thailand (Keller, 1982).

Each of these seven types can be identified by means of routine gemological testing supported by a fade test. Details of the relevant tests may be found in various gemological texts and courses as 
well as in the references cited above. Types 6 and 7 can be identified as synthetic by growth characteristics; the surface-diffusion of type 5 is evident in the localization of the color; characteristic inclusions identify that a type 4 or type 5 stone has been heated (or has not and is therefore type 1, 2, or 3 , in the event that a $\mathrm{CO}_{2}$ fluid inclusion is present, as discussed in Koivula, 1986); an "unnatural" color is a good indicator for type 4 stones, as is Hughes's heating test described above; and spectroscopy (Schmetzer et al., 1983) can be used to identify both types 3 and 4 . This leaves only the question of the presence of the fading types 2 and 7. If, however, the stone loses much of the yellow color on extended exposure to light, it can be identified as either type 2 or 7 . Thus, the "original" natural, untreated type 1 yellow sapphire is material that has fluid inclusions or shows no evidence of having been heated, is not synthetic or diffused, and does not fade on exposure to light.

Although heating, for example to $200^{\circ} \mathrm{C}$ for one hour, can add considerable information as described above, any type of heating, even as low as $60^{\circ} \mathrm{C}$, is definitely not recommended for routine testing of yellow sapphire since it could alter the color of some light-stable type 1 material.

On the basis of the current study, it would seem that the fading of a supposedly heat-treated stone mentioned by Crowningshield in Fryer et al. (1982) was that of an irradiated stone, since it is shown that stones that have been heat treated to high temperatures are stable to light. Another case called into question by the work done here is that of the color center suggested by Schmetzer et al. (1983) as the cause of color in the "burnt" or "annealed" material, here type 4, produced typically by heating above $1440^{\circ} \mathrm{C}$. In view of the stability of the color to the very high temperature of $1440^{\circ} \mathrm{C}$, it is unlikely that the color could be due to a color center; a mere coincidence in the location of the absorption band does not prove an origin. A more probable explanation lies in the exsolution of $\mathrm{Fe}_{2} \mathrm{O}_{3}$, as suggested by Keller (1982); this could happen even if only a small amount of iron is present.

Thus, three distinct groups of color origins appear to be involved in the seven types of yellow sapphire. A color center of unknown nature appears to cause the color in type 1 , which fades with heat and is restored by light. A second, different color center, again of unknown nature, is responsible for types 2 and 7, darkening with irradiation and fading with light or heat. The colors of types 3-6 originate in impurities, such as iron, which can produce a range of colors, depending on the growth and heating history of the material.

Significant loss of color can occur in type 1 yellow sapphires at temperatures well below $200^{\circ} \mathrm{C}$. Irradiation with gamma rays, $\mathrm{X}$-rays, or even ultraviolet can restore the color to type 1 stones and also induces the additional but fading color of types 2 and 7, which can be present together with other types of yellow (e.g., type $1+2$ ). The reaction to irradiation is not affected by heating to temperatures as high as $1700^{\circ} \mathrm{C}$, although such heating may develop the light-stable type 4 yellow in a type 3 stone. The best way to restore the stable state (yellow for type 1 and colorless for types 2 and 7) is exposure to light, typically two days of bright sunlight or longer for less intense (natural or artificial) illumination.

Stable nonfading yellow sapphire clearly does not have a stable color in the absence of extended exposure to light. Exposure to light results in a change to the stable-state color, either from the darker irradiation-induced state or from the lighter heated state. From these observations, it is clear that, as mined, yellow sapphire may be darker than the stable state as the result of a type 2 color component induced either during growth or by irradiation from radioactive material in the surrounding rocks, or it may be lighter from a subsequent heating in the ground, as from a metamorphic process or from intense solar heating. That appears to be the reason that exposure to light is routinely used to establish the stable-state color of yellow sapphire after it is removed from the ground (R. Vinyard, pers. comm., 1986).

The important behavior of the types 1 and 2 yellow sapphire with respect to light, heat, and irradiation is summarized in figure 8. Type 2 yellow sapphire is seen to be merely a special case of type 1 in which the stable state is colorless. Both the stable color of type 1 yellow sapphire as well as the exact temperature for a specific color change in this material can vary from specimen to specimen; presumably it depends on the quantities and types of the color-center precursors present. Even blue sapphire and ruby contain this precursor, and therefore can form some type 2 fading yellow color centers, resulting in green if the blue is fairly pale or "padparadscha" if the red is pale. Nothing definite is known about the precise nature of the defects, which could involve impurities or point 
defects such as vacancies, other than their stability, even at temperatures up to $2000^{\circ} \mathrm{C}$. A possible explanation for the differences between types 1 and 2 yellow sapphires is given in the Appendix.

\section{APPENDIX: COLOR CENTER THEORY APPLIED TO YELLOW SAPPHIRE TYPES 1 AND 2}

The color of type 2 yellow sapphire is caused by a lightfading color center that consists of an electron donor and an electron acceptor of the usual type (see Nassau, 1983, pp. 192-195). On an energy-level scheme, only one absorption level, such as that marked $A b s .1$ in figure 9, is involved. Absorption of irradiation energy /ultraviolet, $\mathrm{X}$-ray, and gamma ray) occurs at this level, with the system falling down into the trapped state via process $A$. Once in the trapped state, the absorption of light produces color via processes $C, D$, and $E$. When barrier $B$ is relatively close in height to the trap level, as drawn in this figure, the energy of light /added to that of room temperature) results in the light-bleaching of type 2 fading yellow sapphire by process $F$. Note that light absorption simultaneously produces color (process $C$ ) as well as bleaching (process $F$ ). For further details on the processes summarized here, see Nassau (1983).

This standard color-center scheme will not, however, explain the behavior of type 1 stable yellow sapphire with respect to heat and light. One possible scheme that can explain this unusual behavior involves an additional, low-energy absorption level, such as $A b s$. 2 in figure 9. This absorption can be activated by light, probably by the more energetic light at the blue end of the visible spectrum, ending up in the trapped state with the formation of the yellow-producing color. Presumably this involves a hole precursor different from the one that produces absorption level 1 .

In the proposed type 1 yellow sapphire scheme, the absorption of light is involved in three processes: production of the color center (process LIGHT), production of color (process $C$ ), and bleaching by the destruction of the color center (process F). The intensity of the yellow color will depend on the relative efficiency of the three processes as well as on the concentrations of the different types of precursors present. Even though heat produces bleaching at a relatively low temperature in type 1 stones, light can repopulate the trap and thus restore the color. One consequence is that such a stone will not have a definite color in the absence of extended

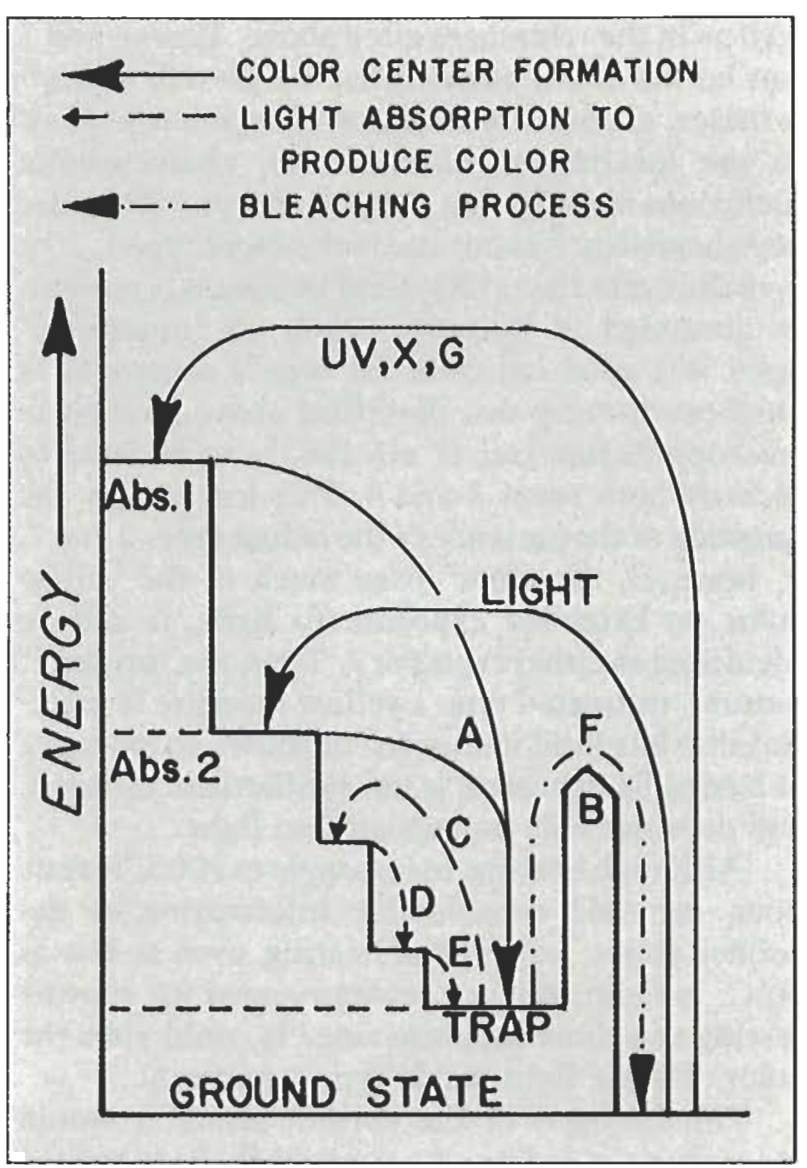

Figure 9. Energy schemes for the color centers of type 1 stable yellow sapphire and type 2 fading yellow sapphire. $U V=$ ultraviolet; $X=X$-ray; $G=$ gamma rays; $A b s .=$ absorption level; TRAP $=$ trapped state.

exposure to light. Another interesting consequence of this scheme is that light of different energy distributions (sun, bright sky, incandescent lamp, fluorescent tube lamp, etc.) could produce sightly different trap concentrations, since the three processes involving light can be expected to have different spectral energy efficiencies. Accordingly, a careful but rapid measurement of the color of a type I yellow sapphire may produce slightly different results from the preceding measurement depending on the type and amount of light to which the stone was last exposed for an extended period.

\section{REFERENCES}

Bauer M. (1904) Precious Stones. Dover, New York.

Crowningshield R. (1983) Padparadscha: what's in a name? Gems e) Gemology, Vol. 19, No. 1, pp. 30-36.

Crowningshield R., Nassau K. (1981) The heat and diffusion

treatment of natural and synthetic sapphires. Journal of Gemmology, Vol. 17, pp. 528-541.

Fryer C., Crowningshield R., Hurwit K.N., Kane R.E. (1982) Gem trade lab notes-sapphire. Gems \& Gemology, Vol. 18 , No. 1, pp. 47-48. 
Fryer C., Crowningshicld R., Hurwit K.N., Kane R.E. (1983a) Gem trade lab notes - sapphires. Gems (4) Gemology, Vol. 19, No. 2, p. 117.

Fryer C., Crowningshield R., Hurwit K.N., Kane R.E. (1983b) Gem trade lab notes - sapphires. Gems \&) Gemology, Vol. 19, No. 4, pp. 236-237.

Hänni H.A. (1986) Korunde aus dem Umba-Tal, Tansania. Zeitschrift der Deutschen Gemmologischen Gesellschaft, Vol. 35, pp. 1-13.

Keller P.C. (1982) The Chanthaburi-Trat gem field, Thailand Gems \&) Gemology, Vol. 18, No. 4, pp. 186-196.

Kelly K.L., Judd D.B. (1955) ISCC-NBS Centroid Colors, Standard References Material 2107; and Color: Universal Language and Dictionary of Names, NBS Special Publication 440. U.S. Government Printing Office, Washington, DC.

Koivula J.I. (1986) Carbon dioxide fluid inclusions as a proof of natural-colored corundum. Gems (4) Gemology, Vol. 22, No. 3, pp. 152-155.

Nassau K. (1980) Gems Made by Man. Gemological Institute of America, Santa Monica, CA

Nassau K. (1981) Heat treating ruby and sapphires: technical aspects. Genis t) Gemology, Vol. 17, No. 3, pp. 121-131.
Nassau K. (1984) Gemstone Enhancement. Butterworths, Boston.

Nassau K. (1983) The Physics and Chemistry of Color. J. Wiley and Sons, New York.

Pough F.H., Rogers T.H. (1947) Experiments in X-ray irradiation of gem stones. American Mineralogist, Vol. 32, No 1-2, pp. $31-43$.

Schiffmann C.A. (1981) Unstable colour in a yellow sapphire from Sri Lanka. Joumal of Gemmology, Vol. 17, pp. 615-618.

Schmetzer K., Bank H. (1980) Explanation of the absorption spectra of natural and synthetic Fe- and Ti-containing corundums. Neues Jahrbuch für Mineralogie, $A b$ handlungen, Vol. 139, pp. 216-225.

Schmetzer K., Bosshart G., Hänni H.A. (1983) Naturallycolored and treated yellow and orange-brown sapphires. Journal of Gemmology, Vol. 18, pp. 607-622.

Smith G.F.H. \{1949\} Gemstones, 10th ed. Pitman, New York. Valente G.K. (1986) AGMS Gemstone Grading Manual, 2nd ed. American Gem Market System, Moraga, CA.

Webster R., Anderson B.W. (1983) Gems, 4th ed. Butterworths, Boston.

\section{i \\ MakeYour Opinion Count VOTE FOR THE GEMS \& GEMOLOGY MOST VALUABLE ARTICLE AWARD}

This is your chance to tell us how you feel about the 1987 volume year of Gems \& Gemology. Your vote gives our authors the recognition and encouragement they devalued subscriber. continues to reflect the needs and interest of the insuse Please choose three articles from 1987 and Your ballot is located on the insert card nefe: (1) first, (2) second, (3) third. Be sure to mark only mark them in order of numerical prefere Additional comments concerning the journal are welcome in the . space provided.
Just mark your ballot, detach it, and drop it in the mail (postage is prepal the must be postmarked by March 7, 1988, to be included in the final tally 8 Gemology. Cash awards of The winning articles will be announced in the Spring $\$ 500, \$ 300$, and $\$ 100$,
third in the balloting. 